\title{
Vínculos Afetivos de Adolescentes Borderline e seus Pais ${ }^{1}$
}

\author{
Aline Bedin Jordão ${ }^{2}$ \\ Universidade Luterana do Brasil (ULBRA), Santa Maria \\ Universidade Federal de Santa Maria \\ Vera Regina Röhnelt Ramires \\ Universidade do Vale do Rio dos Sinos (UNISINOS)
}

\begin{abstract}
RESUMO - Este estudo investigou as características dos vínculos afetivos entre adolescentes com indicadores de organização de personalidade borderline e seus pais. Esses adolescentes foram avaliados por meio do procedimento de estudo de casos múltiplos. Além de entrevistas, foram aplicados o Teste Projetivo Rorschach, o Teste do Desenho da Família e o Inventário de Vínculos Parentais. Os resultados apontaram para vinculações afetivas fragilizadas, permeadas por representações de negligências, abandonos, falta de amparo e proteção. Foram identificadas histórias de vida com vivências traumáticas e violências de diversas ordens. A dimensão transgeracional apareceu em destaque na compreensão dos casos avaliados. Ressaltou-se a necessidade de estudos sobre a adolescência borderline e da ampliação de pesquisas qualitativas sobre o assunto.
\end{abstract}

Palavras-chave: adolescência; vínculos afetivos; desordem da personalidade borderline; psicanálise; transgeracionalidade.

\section{Affective Bonds between Borderline Adolescents and their Parents}

\begin{abstract}
This study investigated the characteristics of affective bonds between teenagers with borderline personality disorder and their parents. These adolescents were evaluated by means of the multiple cases study procedure. Beyond the interviews, the Rorschach Test, the Family Drawing Test and the Parental Bonding Inventory were applied. The results pointed to fragile affective bonds, permeated by representations of negligence, affective abandonment, lack of assistance and protection. Life histories with traumatic experience and violence of several orders were identified. The transgeracional dimension appeared as relevant in the comprehension of the evaluated cases. The need of studies about borderline adolescence were marked as well as qualitative researches about this subject.
\end{abstract}

Keywords: adolescence; affective bonds; borderline personality disorder; psychoanalysis; transgenerationality.

O foco deste estudo foi a caracterização, a análise e a compreensão dos vínculos afetivos de adolescentes com indicadores de organização de personalidade borderline com seus pais ou cuidadores primários. Buscou-se apreender a história de vida desses adolescentes, bem como os eventos significativos na sua trajetória, integrando-os numa compreensão psicodinâmica, e analisando suas repercussões sobre os vínculos afetivos e a organização de personalidade borderline.

A organização de personalidade borderline na adolescência constitui um tema pouco explorado no campo científico. A partir da revisão de literatura realizada, constatou-se que ainda são poucos os estudos que se debruçaram sobre os aspectos vinculares desses adolescentes. Além disso, a grande maioria das pesquisas nessa área trata de pacientes borderline em geral, havendo um predomínio de estudos internacionais e quantitativos.

Assim, considerou-se que o estudo dessas manifestações na adolescência, em especial no que diz respeito às vicissi-

1 Este artigo é parte da Dissertação de Mestrado da primeira autora, realizada no Programa de Pós-Graduação em Psicologia Clínica da UNISINOS - RS.

2 Endereço para correspondência: Rua Ametista, n. 256, Parque Residencial Santa Lúcia. Bairro Camobi. Santa Maria, RS. CEP 97110-772. Fone: (55) 3219-0130 / (55) 9999-6219. Fax: (55) 3220-9231. E-mail: alinejor@terra.com.br, aline_jordão@hotmail.com. tudes dos vínculos afetivos desses jovens, numa abordagem qualitativa de pesquisa, mostra-se como um desafio para a clínica psicológica. Partiu-se do pressuposto de que o significativo número de manifestações borderline na atualidade não pode ser desvinculado do panorama cultural, marcantemente individualista e permeado por funcionamentos familiares muitas vezes conflitivos e instáveis (Birman, 2005; Jeammet $\&$ Corcos, 2005).

Os vínculos constituídos entre pais e filhos exercem um papel essencial na saúde mental e/ou no desenvolvimento de psicopatologias no decorrer da infância e da adolescência. Relações saudáveis do ponto de vista emocional funcionam como fatores de proteção. A qualidade das relações interpessoais e suas representações afetivas desempenham, portanto, um papel essencial na determinação de vulnerabilidades a psicopatologias e na promoção de resiliência e ajustamento psicossocial (Atienza \& Rodríguez, 2004; Brown \& Wright, 2001; Harvey \& Byrd, 2000).

Em contrapartida, vínculos inseguros, desorganizados e indiscriminados mostram-se relacionados ao sofrimento psíquico dos adolescentes, expondo-os a situações de vulnerabilidade emocional e afetiva. Dentre essas situações, situase o adolescente borderline, acentuadamente atuador, com fragilidades significativas nas representações de si (identidade) e dos outros. Trata-se de funcionamentos psicodinâmicos em que predominam angústias primitivas e desestruturantes, intolerância à ansiedade e às frustrações, temor de perda do 
objeto (angústia depressiva) e intensos sentimentos de raiva. A dimensão narcísica encontra-se debilitada nessa organização de personalidade, o que se associa com a precariedade emocional do ambiente em que se deu o desenvolvimento (Baird, Veague \& Rabbitt, 2005; Bradley \& Westen, 2005; Cardoso, 2005; Graña, 2007; Levy, 2005; Maranga, 2002).

Para Levy, Edell e McGlashan (2007) existe uma base depressiva, de cunho fenomenológico, que precisa ser considerada nesses pacientes. A esfera depressiva do borderline associa-se com suas condutas autodestrutivas, comportamentos impulsivos e dificuldades nas relações interpessoais. Da mesma forma, Maranga (2002) refere que o borderline está sempre em busca de "novos investimentos numa procura constante do que nunca teve e se recusa a aceitar que nunca terá, ou seja, um amor incondicional por parte dos objetos primordiais" (p. 222). Trata-se, portanto, de uma depressão de abandono, pelo temor da perda, da solidão, da falta, do desamparo.

Nessa ótica, a literatura tem apontado que as famílias desses adolescentes também se caracterizam por um funcionamento dinâmico borderline, em que imperam as atuações (em detrimento das simbolizações), dificuldades no processo de separação-individuação, denotando um ambiente não responsivo e não protetor, com histórias familiares de abusos e negligências. Constituem-se como núcleos familiares caóticos e instáveis, com dificuldades na comunicação interpessoal e na esfera afetiva (Agrawal, Gunderson, Holmes \& Lyons Ruth, 2004; Bradley \& Westen, 2005; Cardoso, 2005; Fruzzetti, Shenk \& Hoffman, 2005; Graña, 2007; Levy, 2005; Reich \& Zanarini, 2001).

No que diz respeito às relações objetais e às representações dos cuidados parentais, alguns estudos têm sugerido que os adolescentes borderline tendem a representar seus pais como pouco cuidadores e altamente controladores, resultando numa percepção de um holding falho e insuficiente. Além disso, é comum nas famílias desses adolescentes a existência de psicopatologia parental e/ou abuso de álcool ou substâncias e histórias de violências das mais diversas ordens (Barone, 2003; Fruzzetti \& cols., 2005; Helgeland \& Torgersen, 2004; Nickell, Waudby \& Trull, 2002; Russ, Heim \& Westen, 2003). Algumas pesquisas têm se utilizado da teoria do apego a fim de elucidar a associação entre os padrões de apego entre pais e filhos e a etiologia da organização borderline (Agrawal \& cols., 2004; Barone, 2003; Bateman \& Fonagy, 2003; Holmes, 2003, 2004; Levy, 2005; Nickell \& cols., 2002). Nesse sentido, o apego inseguro do tipo desorganizado tem sido o mais fortemente relacionado com essa organização de personalidade. As consequências disso, dentre outras, seriam a diminuição na capacidade reflexiva, a falta de constância objetal, e a construção de modalidades relacionais instáveis, marcadas por idealizações e frustrações constantes (Agrawal \& cols., 2004; Atienza \& Rodríguez, 2004; Bateman \& Fonagy, 2003; Fonagy, Target, Gergely, Allen \& Bateman, 2003; Holmes, 2004; Levy, 2005; Nickell \& cols., 2002).

Faz-se necessário, também, considerar a influência da dimensão transgeracional na dinâmica vincular desses adolescentes, levando-se em consideração que nos resultados da presente pesquisa esse aspecto apareceu com bastante destaque. A vertente da transgeracionalidade tem sido cada vez mais estudada pela psicanálise contemporânea. Entretanto, ainda não tem sido explorada a influência desse aspecto na organização borderline na adolescência. Kancyper (1994/1999) refere que o narcisismo parental constitui-se como um fator que pode dificultar o desenvolvimento da vida subjetiva do filho, já que algumas vezes os filhos permanecem aprisionados aos ideais narcísicos de seus pais, através de uma 'identificação alienante'. A necessária confrontação entre as gerações é condição para que o adolescente possa adquirir sua própria identidade, "efetuando um trabalho diário de reelaboração para conquistar sua condição subjetiva de ser vivo com existência própria" (Kancyper, 1994/1999, p. 85).

Os autores que vêm se dedicando ao estudo da transgeracionalidade têm discutido os mecanismos de projeções, introjeções e identificações, por meio dos quais se operam as transmissões psíquicas - em especial aquelas não elaboradas na história de cada família. Para Correa (2003) e Kaës, Faimberg, Enriquez e Barane (1993/2001), essa transmissão pode ser tanto estruturante (definindo um lugar simbólico de pertencimento na família e possibilitando a reprodução de crenças, valores e princípios familiares) quanto alienante (em que o sujeito fica depositário de conteúdos não metabolizados, não representados, acarretando em atuações e psicopatologias). A transmissão negativa, alienante, retira do sujeito seu discurso singular e o aprisiona nos fantasmas familiares, repercutindo substancialmente no surgimento de sintomas e psicopatologias.Diante do exposto, a pesquisa realizada focalizou os vínculos afetivos de adolescentes com indicadores de organização de personalidade borderline com seus pais, buscando descrevê-los, analisá-los e compreendêlos. A literatura científica e a experiência clínica testemunham a importância da dimensão intersubjetiva/vincular nesse período. Além disso, esses adolescentes mostram-se como um desafio à clínica psicológica, o que convoca à investigação científica.

\section{Método}

\section{Participantes}

Participaram três adolescentes, com idades entre 16 e 17 anos, sendo um do sexo masculino e dois do sexo feminino. $\mathrm{O}$ projeto foi submetido à apreciação do Comitê de Ética em Pesquisa da UNISINOS, e todos os participantes foram detalhadamente informados a respeito do estudo, seus objetivos e procedimentos, concordando em participar.

\section{Procedimento}

Este estudo foi pautado por uma abordagem qualitativaexploratória, a partir da realização de estudos de casos múltiplos (Yin, 2003/2005).

$\mathrm{Na}$ primeira etapa (triagem), os participantes foram acessados em duas escolas de Ensino Médio. A triagem foi baseada na aplicação de dois instrumentos autorrelatados, que foram preenchidos pelos adolescentes: o CBCL (Child Behaviour Checklist - Achenbach, 1991), versão autorrelatada para 
jovens, e o BPI (Inventário de Personalidade Borderline - Leichsenring, 1999). Foram selecionados aqueles que obtiveram escores clínicos tanto nos problemas internalizantes quanto externalizantes no CBCL e os que apresentaram pontuação no BPI indicativa de organização borderline de personalidade. Esses adolescentes foram convidados a participar da segunda etapa do estudo, juntamente com seus pais.

O número de participantes da segunda etapa (estudos de caso) não foi definido a priori, tendo sido utilizado o critério da saturação para a continuidade das avaliações. Nessa etapa, foram utilizados os seguintes instrumentos: (a) entrevistas semiestruturadas com os pais e com os adolescentes, a fim de estabelecer um rapport inicial, e a escuta da história de vida dos pais, dos adolescentes, e da representação dos vínculos afetivos, na perspectiva de ambos; (b) Inventário de Vínculo Parental, desenvolvido por Parker, Brown \& Tuppling, 1979 (traduzido do PBI - Parental Bonding Instrument por (Hauck \& cols., 2006), instrumento autorrelatado que avalia a representação do vínculo materno e paterno por parte dos adolescentes, com base em itens que se referem à percepção dos cuidados recebidos e do nível de controle/superproteção; (c) Teste do Desenho da Família, avaliado pela Escala de Frequência de Sinais Específicos e Escala Global, desenvolvidas por Fury, Carlson e Sroufe (1997) e validadas no Brasil por Cecconello e Koller (1999) e Cecconello, Krum e Koller (2000), escalas estas que analisam as características do apego familiar; (d) Teste Projetivo Rorschach, na vertente interpretativa psicanalítica, a fim de elucidar a psicodinâmica das relações objetais dos adolescentes (Chabert, 1987/1993; Rausch de Traubenberg, 1970/1998).

\section{Análise de dados}

Os dados foram analisados com base no referencial teórico psicanalítico, especialmente nas contribuições dos teóricos das relações objetais, e na revisão de pesquisas sobre os vínculos afetivos dos adolescentes borderline. Como estratégia analítica geral, foi adotado o método de proposições teóricas, de acordo com Yin (2003/2005), tendo sido percorridas as seguintes etapas:

Primeira etapa. Foi realizada uma descrição abrangente de cada caso, organizada de forma 'cronológica' (seguindo os eventos importantes da história de vida dos adolescentes, de acordo com a percepção dos seus pais e a sua própria) e 'temática' - com base nas seguintes categorias de análise: 'vínculos entre os adolescentes e seus pais', conforme foram descritos por ambos; 'eventos significativos de vida' e 'eventos estressores', também na percepção de ambos; 'representações inconscientes das relações com os objetos primários', baseada nos resultados do Rorschach; 'representação dos vínculos de apego', baseada nos resultados do Teste do Desenho da Família; e 'percepção dos cuidados parentais pelos adolescentes', baseada nos resultados do PBI.

Segunda etapa. Foi utilizada a técnica de Construção da Explanação, com o objetivo de analisar exaustivamente os dados de cada estudo de caso e construir uma explanação psicodinâmica sobre o mesmo, e a técnica de Análise de Séries Temporais, na modalidade cronológica, com o objetivo de explorar os eventos ao longo da história de vida do adolescente, identificando presumíveis eventos causais, especificamente em relação àqueles que tiverem impacto sobre as relações objetais significativas do adolescente (Yin, 2003/2005).

Terceira etapa. Foi utilizada a técnica de Síntese de Casos Cruzados (Yin, 2003/2005), com o objetivo de confrontar os resultados obtidos na análise de cada caso, identificando convergências e divergências e buscando, dessa forma, evidências que auxiliassem a responder quais são as características dos vínculos afetivos constituídos entre adolescentes com organização de personalidade borderline e seus pais ou cuidadores primários.

\section{Resultados}

\section{Caso 1: Johnny}

Johnny é um jovem de 17 anos, que atualmente vive sozinho. Seu pai se divide entre a casa do filho e a casa de sua companheira. A gravidez de Johnny não foi desejada nem planejada. Ocorreu num momento em que os pais haviam terminado o namoro, sendo sua mãe ainda adolescente. $\mathrm{O}$ casamento dos pais ocorreu por pressão da avó paterna e o casal foi viver com a avó materna de Johnny.

As relações familiares sempre foram conturbadas, tanto na linhagem materna como paterna. A mãe de Johnny é fruto de uma relação materna extraconjugal, e por muito tempo não sabia disso (embora sempre tivesse desconfiado). Ela tem conflitos até hoje com os irmãos, em função de herança. Sua mãe foi negligente com ela, e sua avó materna também teria sido negligente com os filhos. Além disso, tem uma tia com problemas mentais, e uma outra que se suicidou.

Com relação ao pai de Johnny, sua mãe era a figura autoritária, e o pai era compreensivo, amparava. Houve vários conflitos entre ele e suas irmãs, bem como alguns afastamentos do convívio com sua mãe e seu pai em determinados períodos. Quando sua mãe morreu, ela lhe pediu perdão por tê-lo feito se casar.

O relacionamento conjugal dos pais de Johnny sempre foi instável. Não havia um vínculo forte entre eles. Depois do nascimento do filho, a mãe revelou que engravidou de propósito, e o pai, que não planejava se casar nem ter filhos, declarou que quando o menino completasse 8 anos se separaria. Segundo o pai, a mãe era "desligada", não tinha proximidade afetiva com o filho; era ele quem fazia a função materna: dava mamadeira, trocava e lavava fraldas, fazia dormir, brincava e passeava com ele, mesmo trabalhando muito e ficando pouco em casa. Para Johnny, a referência em termos de carinho, limites e educação é o pai.

O casal se separou quando Johnny tinha 9 anos, sendo que o processo de separação foi tumultuado, demorado e ambivalente. Envolveu muitas brigas, agressões, processo judicial e batalhas financeiras. As brigas do casal também provocaram o afastamento do pai de Johnny de seu próprio pai, sendo que os dois acabaram rompendo e não resgataram sua relação até a morte desse avô paterno.

Johnny referiu que os pais "brigavam direto" na sua infância, o que fazia com que ele se sentisse mal. Seu pai havia 
tido amantes e o filho participava da situação, acompanhando o pai em visitas e viagens com as amantes. Johnny acredita que os pais se separaram porque ele deu um ultimato, dizendo que não aguentava mais a situação. Quando isso de fato ocorreu, a mãe disse para Johnny que não o queria morando com ela. Apesar disso, o filho passava algumas temporadas com a mãe, mas nunca se sentiu muito ligado a ela. Percebe que a mãe também não é ligada nele. Acredita que o desapego da mãe acabou gerando o seu desapego.

A mãe de Johnny teve várias internações por problemas psiquiátricos. Envolveu-se com um jovem viciado em cocaína, foi perdendo tudo o que tinha (carros, dinheiro). Investiu em atividades que não deram certo.

Desde seus 12 ou 13 anos, Johnny faz uso de bebidas alcoólicas e drogas, oscilando períodos de maior ou menor intensidade. Segundo o adolescente, depois da $5^{\mathrm{a}}$ série sua vida "foi um caos, começou a aprender a vadiar". Começou a fazer uso de maconha e cocaína. Passava muito tempo sozinho, podia fazer o que queria. Teve problemas com a polícia, e o pai teve que intervir para que não fosse preso.

Todas as coisas que Johnny "apronta", inclusive na questão das drogas, ele deixa rastros, e sempre o pai fica sabendo. O pai não percebe isso como um pedido de ajuda ou de limites do filho, acredita que ele deixa rastros porque pensa que o pai não vai descobrir, porque se acha esperto. O pai referiu que costuma "largar a corda" para ver onde a situação vai chegar: "eu largo a corda, se ele se enforcar o problema é dele".

A análise do Rorschach revelou que Johnny apresenta um empobrecimento significativo nas suas vivências afetivas e nas relações objetais. Suas representações objetais são precárias e pouco integradas. As relações superficiais são menos comprometidas, embora haja dificuldades nas trocas afetivas e nos contatos sociais.

Identificam-se falhas na sua capacidade de controle afetivo, havendo uma saliência do polo pulsional. Há evidências de conflito com relação à sexualidade e identidade. Sua representação de si é instável e desorganizada, permeada por temores de invasão de conteúdos inconscientes. $\mathrm{O}$ Rorschach evidenciou, ainda, a presença de conflitos com os objetos internalizados. Aponta para vivências negativas com figuras femininas, e dificuldades importantes com a figura materna. Todos esses aspectos sugerem pouca estabilidade nos seus vínculos afetivos, fragilidades dos mesmos, e vivências de desamparo e falta de continência relacionada às figuras parentais.

$\mathrm{O}$ resultado encontrado no Inventário de Vínculos $\mathrm{Pa}$ rentais (PBI) corrobora esses achados, especialmente no que diz respeito à figura materna. A mãe é percebida por Johnny como "Negligente", obtendo resultados baixos tanto no que diz respeito à categoria de "Cuidado materno" como "Superproteção materna". Por outro lado, a percepção dos cuidados oferecidos pela figura paterna indicou "Cuidado ótimo", resultante da categoria "Cuidado paterno", percebido como alto, e "Superproteção paterna", percebida como baixa.

O resultado encontrado nas Escalas de Frequência de Sinais Específicos e Escala Global, aplicadas ao Desenho da Família, foi indicativo de um padrão de apego do tipo inseguro desorganizado.

\section{Caso 2: Natasha}

Natasha tem 17 anos, e mora com os pais e dois irmãos - uma moça de 19 anos e um rapaz de 16 anos. A mãe de Natasha mostra-se como uma mulher cansada, sofrida e passiva, relatando várias dores e sofrimentos. O pai mostrase acentuadamente defensivo e projetivo, minimizando as situações e não se implicando nas mesmas.

Para a mãe, os problemas familiares giram em torno da condição do marido (pessoa complicada, rígida, bebe excessivamente e se descontrola). O pai de Natasha frequentemente, se envolve em brigas, discussões, problemas com a polícia. Faz uso abusivo de álcool e já se envolveu em acidentes. Agride as pessoas fisicamente, inclusive a esposa e a filha, que reclamam da pouca atenção destinada à família.

Sobre a história de vida de Natasha, um fato marcante é que após o nascimento do último filho a mãe entrou em depressão e teve problemas neurológicos (desmaios, ataques epiléticos, perda de memória). Nessa época, Natasha tinha cerca de 3 a 4 anos.

Na percepção dos pais, dentre os filhos, Natasha é a que sempre se destacou, chamando a atenção de alguma forma. Frequentemente "aprontava" na escola, envolvendo-se em confusões e brigas com colegas e professores, matando aula etc. A mãe considera a filha confusa, contraditória, instável, com muitas oscilações de humor e de comportamento. Além disso, percebe que Natasha nunca construiu relações de amizades muito íntimas.

Na percepção do pai, ele tem um bom relacionamento com a filha, e considera que ela o respeita (o que não acontece com a mãe). Disse ser mais explosivo e mais rígido que a esposa, já tendo se utilizado de "surras" na educação dos filhos, principalmente com Natasha. Ele considera Natasha muito "emburrada", sempre insatisfeita e reclamando das coisas. Não permite que as filhas namorem.

Os pais já desconfiaram do uso de drogas por parte de Natasha, pois perceberam mudanças em seu comportamento e incremento da agressividade. Porém, negam a situação, referindo que controlam a filha e acreditando que ela não tem inclinação para isso. Em contrapartida, Natasha relata o uso abusivo de álcool, cigarro e drogas e a falta de olhar dos pais em relação a ela. A jovem ressaltou várias vezes o quanto não se sentia bem em casa, o que a leva a sair para esquecer dos problemas.

Sobre a relação com a mãe, Natasha mostrou-se bastante revoltada e ressentida por não terem uma relação de intimidade. Acha que a mãe não se importa com ela, preferindo os irmãos, e que não a valoriza.

Natasha tem poucas lembranças de sua infância, mas afirmou "carregar um trauma" de ter sido sempre a culpada de tudo entre os irmãos, e a que mais apanhou do pai. Sempre foi vista como, "a que só dá trabalho", "a que só vai pro mau caminho", “a que não presta”. Apesar disso, salientou que sua relação com o pai era muito boa, inclusive parecendo existir uma certa "aliança" e cumplicidade entre os dois.

Natasha se considera uma pessoa muito impulsiva e reativa (envolveu-se em brigas e discussões com professores e colegas). Algumas vezes teve o apoio do pai nessas brigas, embora por outro lado também apanhasse dele pelas reclamações da escola. 
Confia e gosta muito do irmão e já teve sérios problemas com a irmã. Em uma das brigas, a irmã teria dito que ela era adotada e que deveria procurar sua família. Desde então, Natasha desconfia dessa história, e carrega essa dúvida até hoje.

Começou a fumar cigarro aos 13 anos e logo depois maconha e cocaína. Seu vício maior é a cocaína e a cada final de semana a intensidade do uso de drogas vem aumentando. Sempre se relacionou com namorados usuários de drogas e assume que a droga serve como um anestésico, fazendo com que não tenha que se deparar com seus problemas e sofrimentos. Sob efeito das drogas consegue "isolar os pais": "e aí não me atinge em nada". Natasha já chegou em casa drogada várias vezes e seus pais nunca lhe perguntaram se algo estava acontecendo. Nesse sentido, reclamou da indiferença com que se sente tratada em casa: "eles não são de me olhar". Por exemplo, embora ela tenha um piercing (grande e colorido) na língua, os pais nunca perceberam isso.

No que diz respeito aos relacionamentos atuais, tanto as relações de amizade quanto as amorosas são permeadas por inseguranças, dificuldades em confiar e sensação de não ser amada. Como não pode namorar, seguidamente "inventa histórias" para poder sair e se encontrar com o namorado. Segundo ela, os namorados sempre a trataram melhor que seus pais, preocupando-se e importando-se com ela.

A análise do Rorschach mostra a instabilidade afetiva, a falta de controle dos impulsos, a fragilidade identitária e o empobrecimento dos vínculos. Identificou-se também uma elevada instabilidade emocional, com relações interpessoais comprometidas e superficiais, além de vivências de angústias primitivas, de desintegração e desestruturação, fazendo uso de mecanismos de clivagem. O conflito com os objetos internalizados também ficou evidente, a partir da introjeção de figuras agressivas, não protetoras.

O Desenho da Família de Natasha apresentou indicadores de apego inseguro, do tipo desorganizado e/ou evitativo. O desenho mostrou-se empobrecido, sem cor, com poucos elementos, e os que existem denotam tensão, angústia (sombreados, rabiscos), não havendo expressão de afetividade entre os mesmos.

A representação dos cuidados parentais, a partir das respostas ao PBI, remete a um vínculo de "Controle Sem Afeto" em relação à figura materna, e de "Controle Afetivo" em relação ao pai.

\section{Caso 3: Camila}

Camila tem 16 anos, mora com os pais e a irmã caçula, de 9 anos. No ano anterior, teve uma reprovação na escola, bastante frustrante para ela e para os pais. Passou a matar aulas, experimentar bebidas alcoólicas, não investindo mais nos estudos.

Os relacionamentos de Camila são permeados pela sua dificuldade em confiar. Tem poucos amigos íntimos. Nas relações amorosas, evita se envolver e se "apegar", por medo de se decepcionar, sofrer, ser traída, ou por temor à reação dos pais. Por isso, busca estratégias para não se vincular muito, o que lhe causa bastante sofrimento. Os pais não permitem que Camila vá a festas, que namore, coisas que ela faz escondido.
Sente-se insegura de tomar qualquer decisão sozinha. Já se envolveu em brigas e discussões na escola, e se considera explosiva. Já chutou a porta, quebrando-a. Sente-se mal quando se torna explosiva, mas não se sente culpada por isso. Tem pensamentos agressivos em relação aos pais.

A intolerância às frustrações é bastante significativa e Camila já chegou a se autoagredir em algumas ocasiões (já "puxou e arrancou" os cabelos e arranhou o pulso e o pescoço com as próprias unhas). Às vezes têm pensamentos suicidas. Considera-se muito pessimista e "sinistra", sempre achando que algo ruim possa acontecer. Também se considera ansiosa e nervosa, tem insônias. Ao sair sozinha na rua se sente insegura, tem a sensação de que sempre alguém lhe olha e/ ou fala coisas negativas a seu respeito.

A mãe de Camila foi adotada quando tinha 3 anos, mas somente descobriu esse fato aos 15 , por meio de um documento. Teve uma infância marcada por maus-tratos. A mãe adotiva (que não era carinhosa e a surrava muito) nunca assumiu a história verdadeira, e somente após sua morte a adoção pôde se esclarecer.

O pai de Camila foi o primeiro filho entre seis irmãos. Saiu de casa com 13 anos para morar em outra cidade e trabalhar, pois sentia necessidade de ser independente. Relatou que apanhava bastante de seu pai, o que foi mais um motivo para sair de casa. Em relação à adolescência, não lembra de suas vivências. Trabalhava muito nessa fase, o que fez com que agisse de forma mais adulta.

O pai de Camila é bastante racional, prático e concreto em sua forma de analisar as coisas e considera a filha sonhadora. Afirma que ela "foge da realidade", por acreditar que vai conseguir coisas que, para ele, matematicamente, são impossíveis de acontecer (como, por exemplo, a esperança dela em ser aprovada na escola, no ano anterior). Os pais demonstram não acreditar nas capacidades da filha e antecipam desfechos negativos, que muitas vezes se concretizam.

Na última gravidez (época em que Camila tinha cerca de 6 anos) a mãe teve uma depressão "gravíssima", não saía de casa, não queria receber visitas, não tomava banho, o que levou a várias complicações na gestação. Nessa época, Camila ficou "meio de lado" e a mãe conta que percebia a filha muito triste. Nesse período, a mãe fez tratamento medicamentoso para a depressão. Atualmente a mãe diz sentir-se bem e brinca que a filha mais nova e a neta são seus antidepressivos.

A análise do Rorschach revelou dificuldade no controle afetivo, nível elevado de angústia, inibição do pensamento. Essa análise apontou também para a construção de relações afetivas ambivalentes, mais superficiais e menos estáveis. Houve também representações de falta de contenção, falta de fronteiras e limites e dificuldades na internalização de objetos bons e continentes. Há indicadores de angústias diante das perdas e desligamentos, associando-se a sentimentos de vazio e solidão.

A análise da Escala de Frequência de Sinais Específicos e da Escala Global do Teste do Desenho da Família indicou sinais de apego inseguro, do tipo evitativo. O desenho evidenciou um alto nível de vulnerabilidade familiar, tensão/raiva aumentada e distanciamento emocional entre os membros da família.

Sobre sua representação acerca dos cuidados parentais, Camila considerou o vínculo com ambos os pais como de 
"Controle Sem Afeto". Para ela, os pais interferem em suas decisões, invadem sua privacidade e não permitem que realize suas próprias escolhas. Os cuidados parentais também foram sentidos como falhos pela adolescente.

\section{Discussão}

A análise dos dados obtidos nos três estudos de caso indicou, como pontos em comum, histórias de negligência, pouco investimento afetivo, representações parentais permeadas por controle excessivo e pouco suporte emocional, resultando em ressentimentos e sentimentos de desamparo. Além disso, estão presentes fragilidades identitárias, atuações de diversas ordens e dificuldades na construção e manutenção de vínculos afetivos.

A constituição de uma organização borderline de personalidade está associada a um contexto de relações familiares comprometidas, caóticas e instáveis. As inconsistências dos cuidados parentais resultariam em dificuldades na introjeção de um ambiente protetor e acolhedor. Daí as ansiedades de separação e ameaça de aniquilamento por parte desses adolescentes (Atienza \& Rodríguez, 2004; Baird \& cols., 2005; Levy, 2005; Maranga, 2002; Reich \& Zanarini, 2001).

Os resultados encontrados neste estudo articulam-se com esses pressupostos. Nesse sentido, na história de vida de Camila percebe-se um certo descuido e uma falta de olhar dos pais em relação à filha (por exemplo, pela desconsideração do seu sofrimento). Os pais de Camila, frequentemente, não acreditam nas suas capacidades, não valorizam suas conquistas e conferem uma superdimensão às situações negativas, o que repercute em seu senso de não ser amada e não orgulhar os pais. Natasha também apresenta a vivência de não ser cuidada nem amada, em especial em relação à figura materna. A sensação de falta de cuidado por parte dos pais transmite-se aos demais relacionamentos, acarretando prejuízos significativos para os vínculos afetivos. No caso de Johnny, as vivências de desamparo e negligência, no vínculo com a mãe, além das instabilidades e ambivalências no vínculo com o pai, são aspectos decisivos nas suas dificuldades vinculares. A mãe parece não ter conseguido se aproximar efetivamente do filho, investir nele, vincular-se de forma consistente. Os cuidados que dispensou ao menino caracterizaram-se pela distância afetiva, falta de interesse e até mesmo, indiferença. Não é uma figura de referência positiva para Johnny, ao contrário, é percebida como alguém que o rechaçou e abandonou afetivamente.

Alguns estudos apontam uma relação significativa entre experiências de trauma e desenvolvimento de personalidade borderline (Fruzzetti \& cols., 2005; Helgeland \& Torgersen, 2004; Reich \& Zanarini, 2001). Salientam que abusos, negligências, ambiente emocional instável e imprevisível, psicopatologia parental, assim como deficits nos fatores protetivos podem contribuir para seu desencadeamento.

Como vimos, no caso de Johnny estão presentes vários desses estressores: a rejeição materna, a negligência, uma vida familiar caótica, acrescida de alto nível de estresse parental e comunicações disruptivas entre seus pais e de seus pais para com ele. Seu pai, embora se mostrando como uma figura forte, bem sucedida do ponto de vista material, apresenta inconsistências nas suas relações afetivas, na sua capacidade de continência, de tolerância às frustrações, empatia e insight. Tem dificuldades em valorizar as conquistas do filho, faz ameaças de abandono, facilita o uso de drogas e reage agressivamente diante dos problemas que surgem. Não percebe os pedidos de ajuda do filho, expressos de forma indireta (situações que apronta, rastros que deixa). Embora afirmando que o filho é a figura mais importante da sua vida, verbaliza que a qualquer momento é capaz de "largar tudo de mão" e "dar a corda para ele se enforcar".

Camila também tem figuras parentais frágeis: uma mãe depressiva e dependente, e um pai ansioso e com desorganizações na esfera afetiva. Daí as dificuldades da adolescente em se identificar com essas figuras, o que repercute nas fragmentações em seu senso de identidade.

A psicopatologia parental é também evidente no caso de Natasha. O episódio depressivo da mãe em sua infância parece estar na origem das vivências de abandono e negligência de Natasha, repercutindo na fragilidade e pouco investimento no vínculo entre mãe e filha. A trajetória dessa adolescente é permeada pelo uso de violência física (surras) e psicológica (humilhações, desvalorizações constantes). A mãe mostra-se fragilizada do ponto de vista emocional. Parece ter uma precária estrutura psíquica e seu corpo acaba sendo o "palco" em que o sofrimento se expressa. O pai, por sua vez, mostra-se um homem duro, rígido, autoritário. Apresenta dificuldades de autocontrole, o que se evidencia no uso abusivo de álcool e nos envolvimentos frequentes em brigas e discussões. Aplica as leis à família, mas não as cumpre. Reproduz com os filhos a educação que recebeu de seus pais, em que a rigidez e a agressão são preponderantes, mas apresenta um comportamento oposto ao seu discurso.

Lyons-Ruth, Yellin, Melnick e Atwood (2005) encontraram uma associação significativa entre o rompimento das comunicações maternas durante a infância (comportamento frio, distante afetivamente, resposta emocional dissonante) e/ou uma postura inapropriada da mãe no processo de individuação do filho com o desenvolvimento da organização borderline na adolescência. Parece, portanto, que a mãe ocupa um papel central nessa dinâmica. A insuficiente base narcísica da figura materna e as fragilidades de sua constituição psíquica impediriam que ela pudesse exercer a função de objeto narcizizante em relação ao filho, não conseguindo dar sentindo às experiências do bebê. Isso se associa com a inclinação aos actings out, e com as dificuldades nos vínculos afetivos desses adolescentes, observadas neste estudo: tornam-se invasivos, provocativos, sem limites claros entre o eu e o outro e buscam testar as pessoas a fim de se certificarem do seu amor, disponibilidade e confiança.

Com relação à representação dos adolescentes borderline acerca dos cuidados parentais, algumas pesquisas constataram que os filhos frequentemente reportam vivências negativas com seus pais e interações não continentes (Levy, 2005; Nickell \& cols., 2002). De acordo com esses estudos, as figuras parentais são vistas como pouco carinhosas e cuidadoras e altamente controladoras. A partir da interpretação dos resultados do PBI, percebe-se que, na representação dos adolescentes avaliados nesta pesquisa, os cuidadores primários não puderam ser emocionalmente responsivos e 
adequados às suas necessidades, sobretudo as emocionais e afetivas.

Nesse sentido, tanto em relação à figura materna quanto paterna, Camila tem a representação de um alto índice de superproteção e controle e de um cuidado baixo, insuficiente. A relação com o pai é calcada em aspectos lógicos, racionais, materiais, carecendo de componentes afetivos. Natasha também internalizou uma mãe pouco cuidadora e pouco afetiva. Para ela, o vínculo com a mãe é constituído por uma ausência de afeto e muitas atitudes de controle, denotando a percepção de uma mãe emocionalmente fria. Por outro lado, o vínculo de Natasha com o pai configura-se como ambivalente - por um lado há uma idealização dessa figura, por outro, ressentimentos e sentimentos de ódio intensos. Pode-se pensar que a relação afetiva entre pai e filha deu-se pela via da agressão. A forma como ela sentia alguém próximo, alguém que se importava com ela, era por meio das surras que levava. Talvez a necessidade de idealizar esse pai, para além das situações de violência e maus-tratos sofridas com ele, represente uma tentativa desesperada de evitar um estado depressivo subjacente intenso, aniquilador e desestruturante. Se, na figura materna, Natasha não encontra amparo, proteção e reconhecimento, precisa recorrer ao pai, inclusive identificando-se com ele.

Situação semelhante pôde-se observar no vínculo de Johnny com o pai. O "Vínculo Ótimo" representado pelo adolescente também parece uma saída idealizada, diante do vínculo "Negligente" estabelecido com a mãe, a qual não dispensou quaisquer cuidados e/ou proteção, na sua percepção. Assim, o adolescente nega suas dificuldades com o pai, além de evitar se deparar com o sofrimento oriundo da separação da madrasta (com quem havia construído um vinculo maternal), por não conseguir suportar a experiência de abandono e depressão, já vivenciada com a figura materna.

Outro aspecto presente nos vínculos dos adolescentes avaliados, com seus pais, em especial nos casos de Johnny e Natasha, é a inversão de papéis e a indiscriminação entre os sistemas parental e filial. Johnny, por exemplo, percebese como o responsável pela separação dos pais, já que isso ocorreu diante da demanda do filho por uma posição do casal, no sentido de se entenderem ou se separarem. Na família de Natasha, a filha "faz e acontece" com a mãe, chamando-lhe de "velha rabugenta", "louca", mandando-lhe cuidar de seu marido e fazendo críticas sobre o relacionamento conjugal dos pais.

Constata-se que as figuras parentais dos adolescentes desta pesquisa mostram-se confusas, contraditórias, rígidas, intolerantes e inconsistentes. Aparecem falhas importantes na capacidade de suporte emocional e continência afetiva por parte dos pais. Como consequência, ocorre o desenvolvimento de modelos representacionais internos múltiplos, contraditórios e desintegrados, a partir de figuras de apego desorganizadas ou ambivalentes, o que têm sido considerado como fator de risco para a organização borderline na infância e adolescência (Agrawal \& cols., 2004; Atienza \& Rodríguez, 2004; Cardoso, 2005; Levy, 2005; Nickell \& cols., 2002).

Fonagy (2000) assinalou que os cuidados insuficientes no seio de um vínculo de apego inseguro prejudicam o desenvolvimento da capacidade de mentalização, conduzindo às manifestações atuadas. Natasha, por exemplo, está sempre em busca de artifícios para "esquecer" ou "minimizar" o impacto de suas vivências traumáticas na família - aí se situa o uso de drogas, o fato de não querer ficar em casa, estar sempre no centro da cidade, no meio dos guris. Sob os efeitos da cocaína, Natasha "isola" os pais e "ignora" o que viveu de negativo em sua família. Em seu caso, e também no caso de Johnny, as drogas funcionam como anestésicos para a dor e o sofrimento psíquico. Podem significar também uma tentativa de preencher um vazio interior, em função da precariedade de suas bases narcísicas.

As condutas e pensamentos autodestrutivos desses adolescentes também podem ser compreendidos por essa via. As autoagressões de Camila e seu "ódio mortal" direcionado aos pais, além da exposição às situações de risco de Johnny e Natasha, exprimem um pedido de ajuda e limites que dificilmente encontram, na medida em que a presença dos pais não foi suficientemente acompanhada por atitudes de proteção, amparo, segurança e regras firmes, tornando-os sempre muito sozinhos e abandonados aos próprios impulsos e angústias. Exemplos dessa solicitação de contenção é o fato de Natasha chegar em casa drogada, colocar um piercing colorido e grande na língua, "matar" aulas e envolver-se em brigas e confusões. Johnny, por sua vez, deixa rastros em suas travessias pelas drogas, fazendo com que o pai sempre os descubra. E Camila tranca-se em seu quarto, suscitando fantasias de uma provável ideação suicida no pai.

Chamou atenção, nos três casos avaliados, a importância dos aspectos transgeracionais: na história de vida dos pais encontram-se experiências de desamparo, abandono, negligência e violências das mais diversas ordens. Assim, tais vivências parecem estar se transmitindo entre as gerações e repercutindo substancialmente sobre os vínculos afetivos. Aparecem, nos três casos, a não vivência do processo adolescente por parte dos pais, a saída precoce de casa, as representações de abandono e maus-tratos e histórias de rompimentos com figuras significativas de suas vidas.

Destaca-se, na história de Camila, a relação de sua mãe com a mãe adotiva e a biológica e suas frustrações e estados depressivos decorrentes, bem como os maus tratos sofridos pelo seu pai, conduzindo à sua saída de casa, ainda adolescente. Em relação a Johnny, tanto a história de sua mãe como a de seu pai foram marcadas por vínculos afetivos frágeis e conflituosos. Na linhagem materna há indicadores de negligência e fragilidade das relações afetivas em três gerações, pelo menos, incluindo a do próprio Johnny. Na linhagem paterna observa-se uma certa inversão nos papéis exercidos pelas figuras materna e paterna (avós de Johnny), com a mãe exercendo o papel de autoridade e o pai uma função mais amparadora e maternal. Há conflitos acirrados entre os irmãos, principalmente com as irmãs, que também parecem figuras dominadoras e autoritárias na família.

A partir desses atravessamentos transgeracionais, cabe analisar o lugar simbólico que esses adolescentes ocupam em suas dinâmicas familiares. Constata-se, por exemplo, que Camila veio ao mundo para "tirar a mãe da solidão", ocupando um lugar de "antidepressivo" da mãe, de alguém que possa suprir seus vazios e tristezas. Como é impossível cumprir com essa missão, sente que falhou, desvalorizandose e deprimindo-se também, culpando-se e apresentando 
comportamentos e idéias autodestrutivas. Analisando a história de Natasha, um aspecto a ser ressaltado é que os pais tiveram os três filhos "um atrás do outro". Isso, por si só, pode tornar mais difícil a constituição subjetiva da criança, pois no momento em que ela ainda precisa ser o centro das atenções desses pais, um outro bebê já toma a cena. Além disso, durante a gravidez de Natasha, a mãe, além de estar ocupada com a primeira filha, ainda via-se às voltas com as "atuações" do marido. No caso de Johnny, sua gravidez não foi desejada nem planejada e o casal não tinha estrutura material e nem emocional para constituir uma família. Além disso, a mãe assumiu que engravidou para ver-se livre de seu pai e para conseguir se casar. Não havia o desejo pelo bebê em si, mas sim pela "solução" que ele significava para as situações não resolvidas na história dos pais.

Assim, parece não ter sido possível, para esses adolescentes, a internalização de um ambiente suficientemente acolhedor e protetor, o que prejudicou fortemente a representação de si e suas relações objetais. As angústias depressivas e angústias de despedaçamento se fazem presentes em seu funcionamento, denotando uma fragilidade psíquica acentuada, o que está em consonância com a literatura (Bradley \& Westen, 2005; Carvalho, 2004; Reich \& Zanarini, 2001; Russ \& cols., 2003; Villa \& Cardoso, 2004). Os sentimentos de solidão e de vazio apareceram no relato dos três casos avaliados, sugerindo um senso de desamparo e angústias depressivas (Levy \& cols., 2007; Maranga, 2002). Camila apresenta um núcleo depressivo, permeado por sentimentos de desvalorização e desqualificação. No caso de Natasha, a desconfiança de que pudesse ser adotada reforça a ideia de que não se sente amada o suficiente em sua família. Carrega um estigma de que é a que menos teve atenção e a que é vista como estando sempre no "mal caminho", a que sempre apanhou dos pais. Johnny, por sua vez, possui poucas lembranças da infância, e as que consegue relatar têm cunho agressivo ou violento.

As dificuldades atuais na construção e manutenção de vínculos íntimos e duradouros também estão presentes na dinâmica desses adolescentes. As relações de amizade são superficiais, os envolvimentos amorosos são permeados por ambivalências e conflitos. Camila, por exemplo, teme decepções e frustrações, o que faz com que evite se "apegar". Natasha, em seus relacionamentos, tem a sensação de não ser querida e amada. O temor de perda do objeto e de abandono estão sempre presentes nas suas relações afetivas. O modelo de relação conjugal que ela tem é permeado por agressões, desrespeitos, submissões e instabilidades. Embora tenha uma crítica acentuada da situação, parece repetir o mesmo padrão familiar em suas relações. Johnny também parece repetir em suas relações amorosas o modelo de "tudo ou nada" vivido com os pais. Seguidamente "entra de cabeça num relacionamento" (por exemplo, usando anel de compromisso), mas logo se "desliga" e se torna insatisfeito, rompendo a relação.

\section{Considerações Finais}

Os resultados obtidos na análise dos estudos de caso vêm ao encontro do que a literatura tem apontado: a presença de figuras parentais desorganizadas, a frequência elevada de violência familiar e alcoolismo, o contexto familiar negligente e de maus tratos, o temor à solidão, as atuações e angústias depressivas, como fatores nucleares na organização borderline na adolescência. Além disso, relações objetais permeadas por conflitos e ambivalências, denotando, por um lado, uma necessidade intensa de aproximação com os outros (a fim de regular e modular seus afetos e seus medos) e, por outro, sentimentos de raiva, ódio, decorrentes de sensações de rejeição, desvalorização, incompreensão e/ou vitimização por parte destes adolescentes (Baird \& cols., 2005; Barone, 2003; Bradley, Jenei \& Westen, 2005; Bradley \& Westen, 2005; Levy, 2005; Levy \& cols., 2007; Maranga, 2002; Reich \& Zanarini, 2001).

Com efeito, os vínculos afetivos constituídos entre esses adolescentes e suas figuras parentais mostraram-se extremamente instáveis, sensíveis às quebras e rupturas. Daí decorrem as dificuldades no estabelecimento de um senso identitário integrado e, consequentemente, na construção e manutenção de vínculos afetivos saudáveis. A confiança básica necessária para investir em uma relação emocional parece não ter se constituído, dando espaço ao temor do abandono e a sensibilidade às frustrações.

Os maus tratos aparecem na história familiar de todos os participantes (inclusive na dos pais), seja sob a forma de negligência (principalmente em Johnny), de violência física (em Natasha), e de violência psicológica (visualizada nos três casos). Também se podem evidenciar, nos três adolescentes, as vivências de abandono, decorrentes da falta de investimento experimentadas na relação com os pais e, em especial, com a figura materna nos primeiros anos da infância. Camila e Natasha vivenciaram episódios importantes de depressão materna, implicando no afastamento de seus cuidados físicos e psicológicos. Na história de Johnny, também é possível inferir que houve sofrimento materno, dado o relato de internações e uso de medicações psiquiátricas por parte da mãe. Nesse sentido, essas experiências parecem tecer um papel importante no distanciamento emocional entre os adolescentes e suas mães, repercutindo em suas representações de não terem sido suficientemente cuidados e reconhecidos por elas.

Um fator que merece destaque nesta pesquisa é a importância e intensidade dos aspectos transgeracionais nas características e nas conflitivas dos vínculos afetivos desses adolescentes. Essa relação entre organização borderline de personalidade e transgeracionalidade ainda não foi explorada na literatura sobre o assunto, o que instiga a maiores investigações. Diante disso, torna-se relevante aprofundar a compreensão dos atravessamentos da dimensão transgeracional, em especial os efeitos das transmissões negativas, nessa organização de personalidade.

Considera-se importante, portanto, a realização de mais estudos qualitativos, que possam contribuir para elucidar essa temática. A clínica atual de adolescentes cada vez mais tem se deparado com as manifestações limítrofes, o que exige estudos e intervenções coerentes com essa demanda. Por se tratarem de adolescentes, ainda em fase de estruturação, as intervenções nessa fase tornam-se promissoras e possuem também um caráter preventivo. 


\section{Referências}

Achenbach, T. M. (1991). Manual for the Child Behavior Checklist/4-18 and 1991 Profile. Burlington: University of Vermont.

Agrawal, H., Gunderson, J., Holmes, B., \& Lyons Ruth, K. (2004). Attachment studies with borderline patients: A review. Harvard Review of Psychiatry, 12, 94-104.

Atienza, D., \& Rodríguez, B. (2004). El vínculo y psicopatología en la infancia: evaluación y tratamiento. Revista de Psiquiatría y Psicología del Niño y del Adolescente, 4, 82-90.

Baird, A. A., Veague, H. B., \& Rabbitt, C. E. (2005). Developmental precipitants of borderline personality disorder. Development and Psychopathology, 17, 1031-1049.

Barone, L. (2003). Developmental protective and risk factors in borderline personality disorder: A study using the Adult Attachment Interview. Attachment \& Human Development, 5, 64-77.

Bateman, A. W., \& Fonagy, P. F. (2003). The development of attachment -based treatment program for borderline personality disorder. Bulletin of Menninger Clinic, 67, 187-211.

Birman, J. (2005). Mal-estar na atualidade: psicanálise e as novas formas de subjetivação ( $\left.5^{\mathrm{a}} \mathrm{ed}\right)$. Rio de Janeiro: Civilização Brasileira.

Bradley, R., Jenei, J., \& Westen, D. (2005). Etiology of borderline personality disorder: Disentangling the contributions of intercorrelated antecedents. Journal of Nervous and Mental Disease, 193, 24-31.

Bradley, R., \& Westen, D. (2005). The psychodynamics of borderline personality disorder: A view from developmental psychopathology. Development and psychopathology, 17, 927957.

Brown, L. C., \& Wright, J. (2001). Attachment theory in adolescence and its relevance to developmental psychopathology. Clinical Psychology and Psychotherapy, 8, 15-32.

Cardoso, M. (2005). A servidão ao "outro" nos estados limites. Psychê, 16, 65-75.

Carvalho, M. T. M. (2004). Sobre o alcance e os limites do recalcamento nas chamadas "psicopatologias da contemporaneidade”. Em M. R. Cardoso (Org.), Limites (pp. 151167). São Paulo: Escuta.

Cecconello, A. M., \& Koller, S. (1999). Avaliação da representação mental da relação de apego através do Desenho da Família: um estudo com crianças brasileiras. Arquivos Brasileiros de Psicologia, 51, 39-51.

Cecconello, A. M., Krum, F. M., \& Koller, S. (2000). Indicadores de risco e proteção no relacionamento mãe-criança e representação mental da relação de apego. Psico, 31, 81-122

Chabert, C. (1993). A psicopatologia no exame do Rorschach (N. Silva Jr., Trad.). São Paulo: Casa do Psicólogo. (Trabalho original publicado em 1987)

Correa, O. R. (2003). Transmissão psíquica entre as gerações. Psicologia USP, 14, 35-45.

Fonagy, P. (2000). Apegos patológicos y acción terapéutica. Aperturas Psicoanalíticas, 4. Retirado em 02/03/2009, de http:// www.aperturas.org/articulos.php?id=0000104\&a=Apegospatologicos-y-accion-terapeutica.

Fonagy, P., Target, M., Gergely, G., Allen, J. G., \& Bateman, A. (2003). The developmental roots of borderline personality disorder in early attachment relationships. Psychoanalytic Inquiry, 23, 412-459.
Fruzzetti, A., Shenk, C., \& Hoffman, P. (2005). Family interaction and the development of borderline personality disorder: A transactional model. Development and Psychopathology, 17, 1007-1030.

Fury, G., Carlson, E. A., \& Sroufe, A. (1997). Children's representations of attachment relationships in family drawings. Child Development, 68, 1154-1164.

Graña, R. (2007). La psicopatología de la adolescencia y el espectro borderline. Revista de Psicoanálisis Aperturas Psicoanaliticas, 26. Retirado em 09/08/2007, de http://www. aperturas.org/articulos.php?id=0000450\&a=La-psicopatologia-dela adolescencia-y-el-espectro-borderline

Harvey, M., \& Byrd, M. (2000). Relationships between adolescents' attachment styles and family functioning. Adolescence, 35, 345-356.

Hauck, S., Schestatsky, S., Terra, L., Knijnik, L., Sanchez, P., \& Ceitlin, L. H. (2006). Adaptação transcultural para o português brasileiro do Parental Bonding Instrument (PBI). Revista de Psiquiatria do Rio Grande do Sul, 28, 61-68.

Helgeland, M., \& Torgersen, S. (2004). Developmental antecedents of borderline personality disorder. Comprehensive Psychiatry, 45, 138-147.

Holmes, J. (2003). Borderline personality disorder and the search for meaning: An attachment perspective. Australian and New Zealand Journal of Psychiatry, 37, 524-531.

Holmes, J. (2004). Disorganized attachment and borderline personality disorder: A clinical perspective. Attachment \& Human Development, 6, 181-190.

Jeammet, P., \& Corcos, M. (2005). Novas problemáticas da adolescência: evolução e manejo da dependência. São Paulo: Casa do Psicólogo.

Kaës, R., Faimberg, H., Enriquez, M., \& Barane, J. J. (2001). Transmissão da vida psíquica entre gerações (C. Berliner, Trad.). São Paulo: Casa do Psicólogo. (Trabalho original publicado em 1993)

Kancyper, L. (1999). Confrontação de gerações - Estudo psicanalitico (A. V. Fuzato, Trad.). São Paulo: Casa do Psicólogo. (Trabalho original publicado em 1994)

Leichsenring, F. (1999). Development and first results of the borderline personality inventory: A self-report instrument for assessing borderline organization. Journal of Personality Assessment, 1, 45-63.

Levy, K. (2005). The implications of attachment theory and research for understanding borderline personality disorder. Development and Psychopatology, 17, 959-986.

Levy, K. N., Edell, W. S., \& McGlashan, T. H. (2007). Depressive experiences in inpatients with borderline personality disorder. Psychiatric Quarterly, 78, 129-143.

Lyons-Ruth, K., Yellin, C., Melnick, S., \& Atwood, G. (2005). Expanding the concept of unresolved mental states. Development and Psychopathology, 17, 1-23.

Maranga, R. (2002). Organizações borderline: aspectos psicodinâmicos. Análise Psicológica, 2, 219-223.

Nickell, A. D., Waudby, C. J., \& Trull, T. J. (2002). Attachment, parental bonding and borderline personality disorder features in young adults. Journal of Personality Disorders, 16 , 148-159.

Parker, G., Brown, L., \& Tuppling, H. (1979). A parental bonding instrument. Journal of Medical Psychology, 52, 1-10. 
Rausch de Traubenberg, N. (1998). A prática do Rorschach (J. A. Lelé, Trad.). São Paulo: Vetor. (Trabalho original publicado em 1970)

Reich D. B., \& Zanarini, M. C. (2001). Developmental aspects of borderline personality disorder. Harvard Review of Psychiatry, 9, 295-301.

Russ, E., Heim, A., \& Westen, D. (2003). Parental bonding and personality pathology assessed by clinician report. Journal of Personality Disorders, 17, 522-536.
Villa, F. C., \& Cardoso, M. R (2004). A questão das fronteiras nos estados limites. Em M. R. Cardoso (Org.), Limites (pp. 59-70). São Paulo: Escuta.

Yin, R. (2005). Estudo de caso: planejamento e método (D. Grassi, Trad.). Porto Alegre: Editora Bookman. (Trabalho original publicado em 2003)

Recebido em 26.08.08 Aceito em 07.07.09 